\title{
Arqueología de la Arquitectura. Una visión conciliadora desde la Historia del Arte
}

\author{
Archaeology of the Architecture. \\ A conciliatory view from the History of Art
}

\author{
Francisco J. Moreno Martín \\ Universidad Complutense de Madrid \\ franciscojose.moreno@ghis.ucm.es
}

\section{RESUMEN}

El artículo arranca de la discusión entre Arqueología de la Arquitectura e Historia del Arte escenificada parcialmente en las páginas de esta revista. A partir de ahí se profundiza en las relaciones entre ambas disciplinas poniendo de relieve puntos comunes así como divergencias metodológicas. Tras analizar de forma crítica el grado de actualización historiográfica y los diferentes enfoques utilizados por la Historia del Arte en su estudio de la arquitectura histórica se ofrecen caminos que conducen a la colaboración efectiva.

Palabras clave: metodología, formalismo, estilo, tipología, historiografía.

\section{ABSTRACT}

This paper starts with the discussion, partially already published in this journal, between the Archaeology of Architecture and the Art History. Taking that as basis, this work goes deeply into the relationship between these two fields by emphasizing both their common points and methodological differences. After analyzing critically the updated historiography and those different approaches applied by the Art History when studying the historical architecture, some ways of effective collaboration are shown.

Keywords: methodology, formalism, style, typology, historiography.

Recibido: 12 marzo 2014. Aceptado: 16 mayo 2014.

\section{Copyright}

(c) 2014 CSIC. Este es un artículo de acceso abierto distribuido bajo los términos de la licencia Creative Commons Attribution-Non Commercial (by-nc) Spain 3.0. 


\section{1.- Introducción}

A finales del siglo pasado se afirmaba que las ciencias sociales atravesaban un estado de confusión metodológica disfrazada de pluralismo (Aróstegui 1995: p. 131). En el caso concreto del estudio del patrimonio edificado, dicho pluralismo incumbe, entre otras disciplinas, a la Historia del Arte (HA) y a la Arqueología de la Arquitectura (AA), cuyas trayectorias epistemológicas se encuentran en un punto de máxima divergencia (Azkarate 2002, Carrero 2008, Arce 2009, Boto y Martínez 2010, Caballero 2012). Resultaría temerario cuestionar el hecho de que la discusión, más aún en el caso de las ciencias históricas, contribuye a perfeccionar los mecanismos que facilitan el conocimiento de un pasado que, por definición, no se puede ya modificar (Bloch 2006: p. 61). Como historiador del arte convencido de los beneficios que proporciona una perspectiva interdisciplinar de trabajo, me propongo enriquecer este debate añadiendo algunos argumentos a favor del respeto y la comprensión metodológica como únicas vías para la colaboración efectiva. Parto del convencimiento de que el lector de esta revista está familiarizado con el bagaje instrumental de la $\mathrm{AA}$, por lo que me centraré en la presentación crítica de las herramientas que la HA está en disposición de poner en marcha para el análisis de los edificios históricos.

El balance provisional de esta disputa, a la espera de profundizar en los argumentos esgrimidos por unos y por otros, arroja una importante conclusión: pese a los muchos y diversos ámbitos de estudio, la coyuntura actual sitúa a ambas disciplinas en un escenario compartido como es el análisis del patrimonio monumental construido. Como consecuencia de ello el entendimiento es necesario e ineludible (Arce 2009: p. 21, Boto y Martínez 2010: p. 267, Caballero 2012: p. 102). Por mucho que arqueólogos e historiadores del arte nos empeñemos en lo contrario, los "problemas históricos" que plantea la investigación de un edificio son irresolubles desde una perspectiva metodológica exclusivista (Pierotti y Quirós 2000: p. 377). Al contrario, cuanto más avanzamos en nuestro anhelo por reconstruir la complejidad de los fenómenos histórico-constructivos, más necesaria será la convergencia de testimonios de diferente naturaleza y, por ello, de profesionales capaces de enfrentarse a su esclarecimiento (Bloch 2006: p. 69). De seguir discurriendo por senderos paralelos, los resultados de nuestras indagaciones adolecerán del adecuado encuadre cultural (Carandini 1988: p. 33) y, lo que es todavía peor, podrán ser censurados por su desactualización. Estas son las consecuencias directas del desconocimiento y del recelo mutuo.
A tenor de lo expuesto, no resultará superficial efectuar un breve recorrido por los puntos más controvertidos de la discusión con el propósito de subrayar los "reproches" metodológicos emitidos desde uno y otro ámbito".

Tal vez la más recurrente de las críticas, y sin duda la más injusta, hacia la AA es una aparente complejidad terminológica en la presentación de sus herramientas de análisis para el estudio de la secuencia diacrónica de un edificio (Carrero 2008: pp. 6 y 18; Boto y Martínez 2010: pp. 264 y 267). Sus procedimientos han sido banalizados al compararlos con un simple rompecabezas ${ }^{2}$, convirtiendo a la matriz Harris en blanco predilecto de ciertos comentarios irónicos. Merced a esta artificial complejización hermenéutica, los equipos arqueológicos se beneficiarían del acceso privilegiado a tecnologías inalcanzables para grupos de investigación infra subvencionados como los de HA. Un ejemplo de ello sería el de la fotogrametría, cuyos beneficios son, además, cuestionados al compararlos con los de las tradicionales fórmulas de representación planimétrica (Carrero 2008: p. 7, Boto y Martínez 2010: p. 269).

Con todo, la crítica más profunda consiste en minusvalorar la aportación del método estratigráfico a la investigación del monumento, pues en nada mejora a los utilizados por la HA desde sus más tempranos orígenes (Carrero 2008: p. 16). Establecimiento de fases edilicias, identificación de talleres y profundización en las técnicas de construcción han sido tradicionalmente aspectos solventados por los historiadores del arte gracias a la aplicación del método filológico ${ }^{3}$. Es más, la lectura de paramentos había sido ya aplicada en este ámbito antes del desembarco de una "sistematización metodológica tan exhaustiva" como es la que desarrolla la AA. Dicha artificiosidad tendría el propósito de alejarla de los saberes humanísticos y aproximarla a las ciencias sociales y

\footnotetext{
${ }^{1}$ Para la correcta restitución temporal del desarrollo del debate el lector debe ordenar cronológicamente las citas. Observará así como muchos de estos argumentos son, en realidad, "contra-argumentos".

2 Sobre lo improcedente del uso de estrategias de este tipo en la discusión histórica decía Bloch (1999: p. 26) que "si el espíritu crítico tiene tantos detractores se debe, sin duda, a que es más fácil criticarlo o ridiculizarlo que practicar sus rígidos principios...".

3 Llama la atención que, al mismo tiempo, se inste a los historiadores del arte a "interiorizar" los procedimientos de análisis de las disciplinas colindantes como la epigrafía o la numismática (Boto y Martínez 2010: p. 265). La acción de interiorizar consiste en "hacer propio" el procedimiento de otra área de investigación y debe ir precedida de un conocimiento global de sus herramientas epistemológicas (Caballero 2012: p. 106). No parece que los términos en los que se entabla la discusión apunten en ese sentido, como se deduce del uso incorrecto del concepto de matriz Harris así como de la inadecuada sustitución del de "estratigrafía" por el de "disección" (Boto y Martínez 2010: p. 267).
} 
experimentales proporcionándole una "autosuficiencia en sus procedimientos" (Carrero 2008: p. 18, Boto y Martínez 2010: pp. 264 y 267) que supondría -y esta es interpretación mía- un obstáculo insalvable de cara a la colaboración profesional. Según los mismos investigadores, todo esto, sumado a la que consideran como tendencia a la reducción de la arquitectura a un mero proceso material, explica que la AA se vea imposibilitada para abordar el estudio de los contextos sociales y humanos en los que se confeccionaron los edificios (Boto y Martínez 2010: pp. 264 y 268). Bajo su punto de vista, solamente la HA trasciende del análisis objetual para interpretar los usos y las funciones de los espacios que generan las estructuras edificadas.

En última instancia, se culpabiliza a la AA de dinamitar con sus propuestas la compartimentación estilística de la historia de la arquitectura, labor redundante e innecesaria puesto que ya desde las propias filas de la HA se habían dado pasos firmes en esa dirección.

Aunque más adelante tendremos oportunidad de incidir sobre algunas de las frecuentes objeciones que, desde la Arqueología en general, se presentan hacia la HA, en el marco del debate que nos ocupa la principal de todas ellas atañe a la superioridad manifiesta de los análisis visuales de raíz estratigráfica (Arce 2009: pp. 21, 24 y 25). Desde esta perspectiva, aparentemente menor, se cuestiona el planteamiento básico del método histórico-artístico en su vertiente objetual, que no es otro que la definición de estilos a través de la observación y de la comparación. La HA se ve así condenada injustamente al establecimiento de taxonomías agrupadas por estilos que, para colmo, se encuentran sometidas por la tiranía contextual que imponen las fuentes escritas.

Las razones de orden instrumental utilizadas para justificar la superioridad en la observación del alzado de los edificios se encuentran en la revolución que sufrió la Arqueología con la introducción y expansión del sistema Harris (Caballero 2012: p. 102) y, sobre todo, en su aplicación a la cultura material por encima de la cota 0 . Esta mejora en los sistemas de observación y registro no debería confundirse con la búsqueda de una inexistente autosuficiencia metodológica puesto que si "para su uso excavador no se pone en duda su terminología específica (...) ni sus instrumentos (...) ni su proceso, ni sus resultados" ¿por qué se cuestiona cuando el objeto de estudio pertenece a la cultura material arquitectónica ${ }^{4}$ ?

\footnotetext{
${ }^{4}$ El conflicto nace cuando el arqueólogo concibe como parte de esta "cultura material" un tipo de arquitectura que goza del concepto de monumentalidad
}

Existen indicios suficientes como para sospechar que este cuestionamiento recíproco tiene su origen en la convergencia profesional sobre un mismo ámbito de estudio, en este caso la edilicia monumental. Es natural - y todavía lo es más en las circunstancias económicas actuales - que la concurrencia laboral despierte ciertos recelos, pero es preocupante que éstos sobrepasen los límites de las reclamaciones corporativistas (Azkarate 2010: p. 18) hasta convertirse en injustificados ataques entre disciplinas 5 .

\section{2.- Arqueología e Historia del Arte. Encuentros y desencuentros}

De lo expuesto hasta aquí se deduce que detrás de esta disputa metodológica se oculta un desencuentro profesional y académico ${ }^{6}$. Nada de esto debería escandalizarnos, puesto que las cuestiones de método y de competencias resultan clave para comprender las relaciones entre Arqueología e HA desde sus orígenes.

La crítica coincide en señalar a Winckelmann (1717-1768) como el padre de los estudios científicos de ambas disciplinas. Sus estudios consiguen superar definitivamente la visión propia del anticuario, si bien dentro de un marco de referencia cultural exclusivamente clásico (Díaz-Andreu 1995: p. 151). El renovado interés por la observación directa del objeto artístico, sumado a la relectura de las fuentes, alumbraron una Arqueología

(Pierotti y Quirós 2000: p. 378) o, como más tarde hablaremos, de "artisticidad”. Carandini (1988: p. 36) señaló que la nítida -y yo añadiría, pacíficaseparación entre historiadores del arte medieval y arqueólogos medievalistas existió mientras estos últimos se ocuparon "di case di terra, di insediamenti minori, di castelli abbandonati, di campi insomma dove lo storico dell'arte o lo storico dell'architettura non avrebbero mai messo piede".

5 Se ha dicho que la AA persigue intencionadamente proclamar una superioridad científica en el estudio de la arquitectura histórica "buscando apartar a los restantes profesionales que trabajan sobre la materia" además de "dejar a otros científicos fuera de un campo de trabajo que proverbialmente les competía" (Carrero 2008: pp. 10 y 12). Además sobrevuela constantemente la idea de que la irrupción de los estudios estratigráficos ha supuesto la definitiva marginación de los historiadores del arte en los grupos con responsabilidad en la investigación, conservación y gestión del patrimonio edificado (Boto y Martínez 2010: pp. 265 a 268). A decir verdad, la responsabilidad de esta trágica situación debe recaer tanto en las administraciones públicas como en el colectivo de historiadores del arte, incapaz de defender frente a sus responsables la aplicabilidad de sus métodos e instrumentos de trabajo. Por otro lado, tampoco estoy convencido de que se privilegie la participación del arqueólogo en los proyectos de intervención en los bienes inmuebles declarados, dado que no es habitual que sus procedimientos sean de obligado cumplimiento en buena parte de la legislación vigente (Azkarate 2002 y 2008).

${ }^{6}$ Resulta llamativo que un conflicto parecido se haya mantenido en relación al acceso de arqueólogos y de historiadores del arte al cuerpo estatal de conservadores de museos (Borrás 2001: p. 21). Cabe la posibilidad de que uno de los males de nuestra disciplina radique, como este mismo autor indica, en su "débil profesionalización" producto de una manifiestamente mejorable organización de los estudios universitarios. 
y una HA elitistas sometidas a una percepción parcial del concepto de belleza (Ripoll y Ripoll 1988: p. 416). Me interesa subrayar que existe una génesis común para ambas ciencias. La naturaleza ilustrada y academicista, seña de identidad de estos primeros estudios, alcanza también a España donde figuras como Ceán Bermúdez desarrollan una labor que resulta de gran interés historiográfico.

A comienzos del siglo XIX las circunstancias políticas y culturales obligaron a los estados a diseñar estructuras adecuadas para la investigación, la enseñanza y la conservación de su patrimonio histórico artístico. Es aquí donde debemos localizar el primer impulso en la separación entre Arqueología e $\mathrm{HA}^{7}$. Fue la búsqueda de las raíces históricas e identitarias la que permitió redirigir las investigaciones hacia otros periodos históricos $\mathrm{y}$, como consecuencia de ello, a iniciar la renovación en las fórmulas de aproximación a la cultura material. La Arqueología puso su foco sobre la prehistoria y comenzó a explorar instrumentos como la estratigrafía y la tipología. Ambos fueron fundamentales en el progresivo distanciamiento de la disciplina respecto de la raíz filológica que compartía por nacimiento con la HA (Díaz-Andreu 1995: p. 152).

Mientras la Arqueología profundizaba en los métodos de aproximación al objeto, la HA comenzaba a transitar por la senda teórica que caracterizaría su posterior evolución. Pese a estar ya establecidas las bases conceptuales sobre las que se asentó esta incipiente separación, todavía tardó en extinguirse un perfil profesional que, con amplias responsabilidades en el cuidado del patrimonio, reunía en sí mismo las figuras de arquitecto, historiador del arte y, en ocasiones, incluso arqueólogo ${ }^{8}$.

Durante las primeras décadas del siglo XX, la Arqueología inició la búsqueda de instrumentos mediante los cuales dar respuesta a las necesidades generadas en el trabajo de campo, al compás de la extensión del conocido como método Wheeler de excavación. La base estratigráfica de dicho sistema provocó el redimensionamiento del valor de los materiales hallados. Bajo

\footnotetext{
7 Países como España y Francia vieron incrementada la responsabilidad en la gestión de sus respectivos patrimonios nacionales como resultado de procesos desamortizadores. Pese a que dicho procedimiento conllevó pérdidas irreparables, lo cierto es que el volumen de piezas a inventariar, catalogar y, llegado el caso, vender o exponer, obligó a la dinamización y evolución del conocimiento científico en el ámbito artístico, incluida la arquitectura.

${ }^{8}$ Véase el caso de Viollet-Le-Duc (Carandini 1988: p. 31) y Choisy (Mandoul 2005: p. 138) en Francia o, por mencionar algunos de los más conocidos, Demetrio de los Ríos, Adolfo Fernández Casanova, Aníbal Álvarez o Vicente Lampérez en España.
}

esta nueva perspectiva, el objeto, como si de un fósil se tratara, cobraba un valor topográfico que trascendía del puramente material, o dicho de otro modo, el objeto arqueológico fue perdiendo progresivamente su valor artístico (Díaz-Andreu 1995: p. 156).

Por su parte la identidad teórica de la HA se vio reforzada a partir de las reflexiones generadas en el seno de la llamada Escuela de Viena, atenta a la imparable evolución (o "revolución") experimentada por la práctica artística en el cambio de siglo. Nacidas al amparo del clasicismo dieciochesco de cuño filológico, en apenas cien años la Arqueología y la HA habían reconducido sus objetivos y métodos de trabajo hacia caminos completamente distintos.

Mientras que en otros países europeos esta brecha tuvo su eco en la organización de las estructuras académicas y de investigación, en España la distinción no fue efectiva. En el Centro de Estudios Históricos, creado en 1910 al amparo de la Junta de Ampliación de Estudios, la sección de Arqueología y Arte Medieval fue sustentada por figuras de la talla de Manuel GómezMoreno o, posteriormente, Leopoldo Torres Balbás. Ambos investigadores, amén de ejemplificar la indefinición existente entre HA y Arqueología, ocupan un lugar destacado como mentores de sucesivas generaciones de historiadores del arte, arqueólogos y/o arquitectos, que contribuyeron a la consolidación de sus respectivas disciplinas (Borrás 2001: p. 30). También actuaron como canalizadores de las escuelas teóricas foráneas y fueron impulsores de la revista Archivo Español de Arte y Arqueología, fundada en 1925 y cuyo título nos advierte de la fructífera hibridación metodológica del momento.

Mientras se gestaba la separación entró en escena una trascendental novedad historiográfica. Durante el período de entreguerras se alumbró en Francia la Nueva Historia, corriente teórica que sirvió como estímulo para la renovación de otros ámbitos del conocimiento humanístico, entre ellos la Arqueología (Ripoll 1992: p. 91). A medida que historiadores como Bloch o Febvre acuñaban conceptos como "cultura material" o "historia desde abajo", arqueólogos como Lamboglia fomentaban la excavación estratigráfica y los estudios de las tipologías cerámicas con un doble objetivo. Se perseguía afinar en las dataciones al tiempo que se utilizaban estos objetos de la vida cotidiana para confeccionar discursos históricos alejados de la perspectiva aristocrática cercana a los trabajos de HA (Ripoll y Ripoll 1988: p. 423, Ripoll 1992: p. 92). En última instancia, a lo largo de las décadas finales del siglo pasado se asistió a la irrupción 
de la escuela anglosajona de Arqueología que tuvo una profunda influencia en el ámbito mediterráneo, especialmente dentro de la Arqueología medieval. Este fenómeno contribuyó a la reafirmación de sus bases metodológicas estratigráficas y tipológicas y, con ello, a la ruptura definitiva respecto de la HA (Carandini 1988: p. 32).

A pesar de la honda fractura epistemológica, no han faltado las voces de quienes reivindican y practican meritorios estudios colaborativos, alimentándose así un debate que no es exclusivo de la academia española. En Italia, sobre todo en el terreno de la Arqueología clásica, investigadores de la talla de Bianchi Bandinelli o el propio Carandini apostaron por el entendimiento efectivo, no sólo entre arqueólogos e historiadores del arte, sino también con los arquitectos, como vía para la construcción de un único relato histórico (Ripoll y Ripoll 1988: pp. 412 y 426, Ripoll 1992: p. 92, Miranda 2000: p. 512, Brogiolo 2002: p. 22). Por el contrario, desde ciertos sectores de la Arqueología medieval, la HA ha sido relegada por su impreciso funcionamiento cuando la escala del análisis se reduce (Mannoni 1988: p. 414), así como por las deficiencias demostradas a la hora de aportar dataciones dentro de ambientes constructivos tendentes a la pervivencia de formas y técnicas (Parenti 1988: p. 282, Pierotti y Quirós 2000: p. 379).

Por ajustarse a la idea que yo mismo defiendo, me gustaría destacar la opinión de Brogiolo (1995: p. 32, 2002: 22), puesto que considera la alianza entre AA e HA como el único camino válido a la hora de compensar las inconsistencias que ambos procedimientos presentan por separado. Se atreve a proponer la formación doble como la mejor solución para canalizar y poner en marcha este procedimiento. De acuerdo con esta idea, la interiorización metodológica recíproca, real y efectiva señalaría el camino más adecuado. Para ello debemos asumir un cambio en la dinámica formativa que ayudará a redefinir los métodos de "estáticos" a "itinerantes". En cierto modo, algo similar sucede ya con uno de los pilares de la AA, la estratigrafía, nacida en el marco de la geología y adaptada para su uso adecuado en el análisis del yacimiento y del edificio9 (Caballero 2012: p. 106).

\footnotetext{
${ }^{9}$ La utilización de la estratigrafía como apoyo para el estudio de obras de arte es un hecho común. Es frecuente su presencia en los informes de restauración y estudio de la pintura. Como es lógico, tales estratigrafías documentan en exclusiva cortes verticales, pero la aplicación rigurosa de dicho método permite aislar tanto las capas de policromía originarias como las interfaces que revelan repintes posteriores. Por ello la limpieza de la obra ha pasado de ser un proceso restaurador a una actividad que recupera información valiosísima sobre la misma. Quienes se han aproximado a este método desde la restauración consideran que la aparente sencillez de los análisis realizados
}

Las condiciones impuestas para la correcta asimilación de estas "metodologías itinerantes" son las lógicas cuando se pretende traspasar las barreras impuestas por la práctica científica académica: una comprensión profunda y una puesta en práctica rigurosa.

Entiendo que los postulados de la AA son ya de sobra conocidos por los lectores de esta revista ${ }^{10}$, de manera que mi propósito a partir de este punto será el de clarificar ciertos procedimientos de la HA y poner el acento sobre aquellos métodos y enfoques que, solos o en combinación con la AA, son útiles para el mejor conocimiento de la edilicia histórica. Intento con ello levantar un primer peldaño para el reencuentro entre ambas formas de concebir el estudio de la arquitectura. Fue Carandini (1988: p. 38) quien vaticinó este reencuentro a un nivel superior, puesto que cada una de ellas por separado habrá perfeccionado los métodos que le son propios.

\section{Análisis objetual y análisis contextual}

Partiré de la idea de que el propósito principal de la Arqueología y de la HA consiste en reconstruir la historia a partir del estudio de objetos. Hemos de asumir, no obstante, que el relato compuesto a partir de nuestras indagaciones es inexacto porque la recreación completa de los acontecimientos del pasado resulta científicamente imposible (Asti 1973: p. 129). ¿Significa esto que debemos renunciar al reconocimiento científico para nuestras investigaciones? En absoluto. Sucede que el criterio de "cientificidad" no debe aplicarse sobre nuestras hipótesis, sino que ha de servir como mecanismo mediante el cual debemos controlar los procedimientos utilizados en la aproximación al objeto de estudio (Pizza 2000: p. 47). Dicho de otro modo, el rigor del trabajo del historiador se sustenta, fundamentalmente, en el método elegido para extraer la información de los materiales con los que trabaja.

Se ha definido método como un "procedimiento, o un conjunto de procedimientos, que sirve de instrumento para alcanzar los fines de investigación (...) que puede ser común a varias ciencias" (Asti 1973: p. 16). Una ciencia

(hay que tener en cuenta el alcance limitado de las secuencias documentadas) no debería ser obstáculo para la confección de un marco teórico que ayude a consolidar el rigor que aporta este tipo de estudios (Barros 2010).

10 Como historiador del arte formado como arqueólogo de la arquitectura considero que las mayores diferencias de procedimiento con respecto a mi propia práctica, y por tanto las que más y mejor debemos esforzarnos por aprehender son: la necesaria aproximación estratigráfica y tipológica, el manejo de planimetrías adecuadas a la precisión del análisis y, en última instancia, el insoslayable trabajo en equipo que fundamenta la discusión pormenorizada (base de este tipo de trabajos). 
concreta se distingue del resto en la utilización de sus propias técnicas (o enfoques), que son resultado de la aplicación práctica de dichos procedimientos. Igualmente, la mejoría del método es fruto de la experiencia ${ }^{11}$, pues éste se moldea y se adapta para dar respuesta a las exigencias generadas durante la investigación (Pächt 1986: p. 9).

Como ya se ha expuesto, la HA y la Arqueología nacidas a fines del XVIII parten de una raíz metodológica común que privilegiaba el uso de los testimonios escritos sobre el análisis de las piezas. Quiere esto decir que estuvieron unidas en sus orígenes a través del "método filológico". La introducción del pensamiento científico en las disciplinas responsables de la construcción histórica planteó nuevos retos que obligaron al diseño de renovadas estrategias con las que superar la reducida visión del pasado que ofrecían los documentos y los textos.

Inevitablemente, esta encrucijada produjo una división metodológica que todavía hoy permanece abierta. La Arqueología, sin abandonar plenamente el uso de los testimonios escritos, persiguió su autonomía a través de la adopción de la estratigrafía, método que comparte con la geología. La HA se mostró reacia al abandono definitivo de la seguridad que suministran las fuentes y construyó su especificidad a partir del formalismo propio del positivismo decimonónico combinado con la reflexión teórica en torno a los componentes y al alcance del objeto artístico. La distancia entre disciplinas se vio incrementada como resultado de las divergencias en la elección del método de aproximación a lo que hoy denominamos "cultura material". Mientras la forma es el parámetro principal en la configuración de un estilo artístico, para la Arqueología la variable taxonómica es una más en la construcción de series tipológicas de materiales cuyo valor como herramienta de conocimiento histórico radica fundamentalmente en su posición dentro de la secuencia estratigráfica.

En la práctica, esto supone que una investigación histórico-artística original deberá combinar el análisis contextual con otro de carácter objetual ${ }^{12}$ (Freixa 1990: p. 74). Objeto y contexto configuran un binomio ineludible $\mathrm{y}$ fundamental para la consecución de los objetivos fijados y sólo un estudio adecuado habilitará la posibilidad

\footnotetext{
11 Vale la pena señalar que la historiografía de la HA en España se ha caracterizado por un cierto desfase metodológico. Basta señalar como ejemplo que la implantación del método formalista, nacido en el siglo XIX, se produjo tardíamente, careciendo del necesario recorrido para su maduración, debate y superación (Borrás 2001: p. 69).

${ }^{12}$ Con matices, puesto que existen importantes estudios de HA que se limitan al ámbito contextual (trabajos documentales sobre artistas, obras o periodos concretos, colecciones de fuentes, etc.).
}

de pasar a la interpretación o especulación. El proceso de investigación se sitúa en "una fase centrípeta en la que se organiza toda la información (...) a fin de convalidar la hipótesis de partida" (Pizza 2000: p. 70). Se puede hablar de dos niveles distintos:

a) Acumulativo. Recogida de datos a través del análisis combinado tanto contextual como objetual. En primera instancia, la obra de arte se estudia desde una perspectiva filológica/documental con el propósito de recomponer de la manera más precisa posible el contexto en el que fue creada, recibida, utilizada/modificada $y$, en ocasiones, destruida ${ }^{13}$. Posteriormente, en la medida en que sea posible, se procederá a su estudio directo con el propósito de realizar una correcta clasificación estilística. A la adecuada catalogación se llega gracias a la puesta en marcha del método de observación y comparación. Contemplamos rasgos formales y técnicos, buscamos equivalencias entre éstos y los que caracterizan al estilo predominante para el horizonte cronológico ofrecido por las fuentes.

b).Interpretativo. La confección de la historia, sea desde los documentos sea desde los objetos, nos obliga a no detenernos en el análisis objetual y a trascender la mera recolección de datos (Pächt 1986: p. 106). Nuestra obligación es la de explicar los rasgos de la obra final, así como todo lo relativo a su realización, recepción y uso. Aquí nos situamos en una fase "centrífuga en la (...) cual se ramifican caminos interpretativos en dirección a las revaloradas densidades semánticas del dato" (Pizza 2000: p. 70).

Es evidente que la fractura metodológica entre Arqueología e HA se localiza dentro del nivel acumulativo, en el momento de la obtención de la información. Ante esta realidad cabría preguntarse ¿cómo se enfrenta el historiador del arte a la recogida de datos procedentes del objeto y del contexto en el que fue realizado? ¿Qué rasgos definen nuestra capacidad analítica frente a la de otros profesionales?

El análisis contextual suele preceder al trabajo de campo, llegando a convertirse en ocasiones en el propósito mismo de la investigación. El estudio de las fuentes ha sido considerada por Schlosser como la labor a la que la "historia del arte debe su naturaleza mucho más

\footnotetext{
${ }^{13}$ Contexto histórico y, por lo tanto, susceptible de ser reconstruido mediante el uso de las fuentes. No debe confundirse con el concepto de contexto arqueológico, término que se utiliza para definir un estrato en el que se inscriben relaciones de tipo contextual (Caballero 1996: p. 62).
} 
rigurosamente científica" (Cfr. en Pizza 2000: p. 45). Por tratarse de un método instrumental, es compartido con otras muchas ciencias formales y humanas (Bloch 2006: p. 58).

Lo que nos diferencia del historiador que trabaja exclusivamente con documentos es que nuestra principal fuente de información es la propia obra de arte. A través del análisis objetual se procede a la verificación material de los datos textuales. La lectura de la obra requiere de la aplicación de un método adecuado y riguroso puesto que "leer o descifrar un cuadro o un monumento no es tarea de un instante por medio de una aprehensión espontánea (...) son necesarias horas —o días - para asir realmente su significación" (Francastel 1972: p. 15). Por supuesto, no se trata de una observación pasiva sino una labor analítica que concluye con la descripción pormenorizada de los aspectos morfológicos, materiales y técnicos que facilitan su comparación y posterior encuadramiento estilístico (Schapiro 1953: p. 280 y Freixa 1990: p. 80), asumiendo que, por muy objetivo que se pretenda ser, resulta inevitable traspasar la frontera de la interpretación (Pächt 1986: p. 86). Por tanto, la comprensión de la imagen para su posterior definición estilística es un proceso que se fundamenta en el mecanismo sensorial de "ver" o "contemplar"14 (Fernández Arenas 1982: p. 139). La mirada del experto ha sido forjada en la asimilación natural de este proceso, de manera que esta "habilidad" se entiende como pieza clave en la profesión del historiador del arte (Freixa 1990: p. 75).

El estilo, como categoría visual, guarda relación con un determinado periodo crono-cultural consensuado previamente por parte de la historiografía. Esto explica su potencialidad como herramienta para prefigurar horizontes históricos, además de para identificar modificaciones sobre la obra originaria (Schapiro 1999: pp. 78 y 79).

Observación y comparación preceden a la identificación estilística. Sin embargo, el método comparativo, como operación intelectual, no es exclusivo de la HA y se encuentra en la raíz de todas las ciencias humanas (Bloch 1999). Este mecanismo permite sobreponerse a la ausencia de referencias históricas concretas gracias al establecimiento de relaciones de filiación y/o dependencia entre fenómenos análogos surgidos en diferentes medios sociales. Desde la historiografia, este procedimiento está sujeto a unas normas de las que depende la validez de los resultados obtenidos. Solamente la selección adecuada de los sistemas sociales de comparación, tanto en términos

\footnotetext{
14 Lo que Boto y Martínez (2010: p. 264) denominan "exploración óptica".
}

territoriales como temporales, garantiza no cometer el error de confundir influencia con coincidencia fortuita.

También dentro de la HA se han denunciado los riesgos que corre la disciplina al utilizar indiscriminadamente la comparación como método de trabajo. El mayor de todos ellos es el de caer en la autosugestión que suele preceder a la búsqueda de infundados paralelos taxonómicos (Pächt 1986: pp. 81 y 82). Si no respetamos las reglas básicas de toda comparación - especialmente la colocación en el mismo plano temporal de los elementos comparados - ésta se queda en mera concordancia.

\section{La HA frente a los retos de la "nueva historia"}

Una adecuada contextualización crono-cultural contribuye a dotar a la obra de arte de valor documental. Esa es la razón por la que la HA, al contrario de lo que sucede con la crítica, se ocupa de la dimensión histórica de la producción artística (Fernández Arenas 1982: p. 20). Sin embargo, la tensión entre estética e historia ${ }^{15}$ es consustancial al propio hecho artístico y el conocimiento histórico que arroja su análisis está lastrado por la exclusión de todo aquello que no alcance el mínimo exigible de un concepto tan subjetivo como es el de artisticidad (Pächt 1986: pp. 10 y 113). Esta afirmación cobra gran trascendencia cuando la obra objeto de análisis es un edificio histórico (García Granados 1992: p. 64), siendo éste un aspecto negativo que no ha pasado desapercibido entre las filas de la AA (Mannoni 1988: p. 415).

La crítica emitida es tan contundente como comprensible: a partir del instante en el que un estudio sitúe su foco sobre valores formales y de uniformidad estilística, se está condenando a permanecer en la penumbra histórica a un elevado número de construcciones cuyo uso secular ha provocado la deformación, distorsión o pérdida de dichos valores. Paradójicamente, es en la alteración y en el cambio donde se concentra la sustancia de la información histórica, de manera que si el análisis carece de los medios para detectar las modificaciones

\footnotetext{
15 El desapego respecto de las fuentes sumado a la fuerte carga teórica que en el siglo XIX caracterizó a la corriente formalista basada en la "pura visualidad" (Fiedler 1990: p. 43) se sitúa en el origen de esta división entre una HA tendente hacia el análisis estético y otra de cuño positivista más histórica. Respecto de la primera, son muchas las críticas lanzadas desde posiciones sociológicas. La pérdida de la referencia histórica conduce a la pura especulación estética (Francastel 1972: p. 13). Fernández Arenas (1982: p. 21) advierte del peligro que supone que "el historiador del arte se detenga sólo en el valor estético y morfológico sin profundizar en el significado del arte, como síntoma y documento del momento histórico en el que nació". Por su parte, Debray (1994: pp. 109 y 129) propone la vía intermedia como la solución, puesto que abandonar la vertiente estética supondría renunciar a hacer HA.
} 
provocadas sobre la estructura de origen verá mermado su interés histórico (García Granados 1992: p. 64 y Fernández Arenas 1982: p. 150). En mi opinión, el historiador de la arquitectura comete una imprudencia al renunciar a aquellas alternativas metodológicas que le permitan rehabilitar el edificio, tanto en su estado inicial como en los muchos estados intermedios por los que la fábrica ha transitado hasta llegar a nuestros días.

La lectura crítica del documento (en nuestro caso un documento "construido") y la detección de las mutaciones del fenómeno histórico a través de la "larga duración" son dos de las ideas sobre las que giró la renovación de la ciencia histórica durante el siglo pasado. No podemos dudar de la validez de estas reflexiones para los estudios histórico-artísticos. Tanto es así, que la obra de arte ha llegado a ser definida como el medio "vivo" y "objetivo" a través del cual captar los cambios que jalonan los grandes períodos de la historia (Francastel 1972: p. 18). De entre todas destacan los edificios, capaces de encerrar en sí mismos mejor que cualquier otro producto artístico la dimensión temporal (Zevi 1951: p. 23).

Si la historia del arte en general, y de la arquitectura, en particular, reclaman legítimamente formar parte del conjunto de saberes que contribuyen a mejorar nuestro conocimiento del pasado, resulta lícito interrogarse acerca de en qué medida, desde estos ámbitos, se ha tenido en cuenta la evolución experimentada por la Historia en su último siglo de vida. Establecer el grado de actualización teórica no es una cuestión menor (Fernández Arenas 1982: p. 15). Si nuestro propósito radica en contribuir al conocimiento del pasado a partir del estudio de la arquitectura histórica, creo que merece la pena ver si los procedimientos e instrumentos aplicados concuerdan con los de quienes, con este mismo objetivo, utilizan otros recursos de acceso a la información ${ }^{16}$.

Documentos y textos constituyen la base tradicional de toda investigación histórica desde el origen de la disciplina. Su madurez científica se alcanzó en el siglo XIX a partir del rechazo de la mera descripción a favor del positivismo fundamentado en el trabajo metódico sobre las fuentes (Aróstegui 1995: p. 99). A lo largo de la primera mitad del siglo XX esta visión feliz respecto a los documentos viró hacia el criticismo, lo cual supuso una auténtica revolución en el método que, indirectamente, afectó a otras ramas del conocimiento humano. En este interesantísimo proceso juega

\footnotetext{
${ }_{16}$ Esta misma reflexión puede encontrarse desarrollada en el recomendable trabajo de Pizza (2000).
}

un papel trascendental la conocida como Escuela de los Annales (Pizza 2000: p. 40).

Las valiosas aportaciones vertidas por las distintas generaciones de historiadores vinculados a este grupo sobrepasan con creces los límites de este trabajo. Me limitaré a sintetizar aquéllas que considero de utilidad para el propósito fijado.

- A una historia superficial sustentada en la descripción de acontecimientos oponen otra compleja e interpretable que cuestiona la atomización que supone concebir el pasado como una mera ordenación cronológica de "hechos" (Aróstegui 1995: p. 104, Pizza 2000: p. 46). De una "historia-relato" se pasa a una "historiaproblema".

- Abogan por la superación de los límites impuestos por el documento escrito y, como consecuencia de ello, proponen la ampliación del repertorio de fuentes y evidencias hacia otros ámbitos de las ciencias sociales y humanas (Aróstegui 1995: pp. 104 y 105). Si la historia es una, no existe justificación para persistir en la compartimentación académica de su estudio (Pizza 2000: p. 45). Denuncian la necesidad de contar con los datos arqueológicos, si bien advierten de que éstos, al igual que los textos, pueden haber sido alterados voluntariamente (Bloch 2006: pp. 57 y 71).

- Apuestan por el trabajo en equipo antes que por la multiplicidad de aptitudes. La especialización contribuye a aumentar la intensidad del trabajo de investigación, pero debe llevar asociada la puesta en común de estos esfuerzos (Bloch 2006: p. 88).

- La posición del historiador frente al documento debe ser profundamente crítica. Reflexionar sobre su veracidad externa e interna. Renunciar a esta perspectiva empobrece la investigación al tiempo que ratifica la pereza consustancial a la condición humana (Bloch 1999: p. 21). Se promocionan los estudios desde el interior del mismo documento, desestructurándolo, analizándolo pormenorizadamente hasta llegar a establecer unidades y sus relaciones (Pizza 2000: p. 63) ${ }^{17}$.

- Como consecuencia de todo lo anterior, denuncian las visiones que reconstruyen la historia a partir de narraciones nacidas al amparo de grupos sociales históricamente privilegiados. Tras esta reflexión surgirán conceptos tales como los de "representaciones colectivas" o "historia de las mentalidades", así como

\footnotetext{
17 Nótese la similitud con el análisis estratigráfico, puesto que equivale a analizar contextos.
} 
estudios cuyo objetivo es la recuperación de la vida cotidiana a través de la indagación material de las distintas civilizaciones (Pizza 2000: pp. 41 y 53).

- Contribuyen a cambiar la visión estática del tiempo histórico por otra más dinámica. El pasado no estará surcado de acontecimientos sino de estructuras cuya indagación debe ser proyectada desde el análisis de sus cambios. Plantean, dicho de otro modo, una concepción "estratigráfica" de lo real.

Otros dos focos de renovación historiográfica que vieron la luz a mediados del siglo pasado deben ser obligatoriamente tenidos en cuenta en un análisis como el que venimos desarrollando. La llamada escuela marxista parte del convencimiento de que el motor que provoca el cambio histórico es el conflicto generado entre fuerzas productivas (Aróstegui 1995: p. 111). Este enfrentamiento de clases, como veremos, puede trasladarse también a la producción artística (Hadjinicolaou 2005: p. 7). Por otro lado, la variante historiográfica basada en la matematización de modelos de comportamiento a través del registro numérico en el largo plazo (Aróstegui 1995: p. 121) generó una visión cuantitativista de construcción del relato histórico no exento de críticas ${ }^{18}$.

A partir de los años 80 se produce una profunda crisis de estos paradigmas y, como consecuencia de ella, una cierta renovación metodológica no exenta de confusión. En esta interesante encrucijada convergen propuestas nuevas con otras que miran hacia el pasado para encontrar la inspiración epistemológica. Lo más llamativo para nuestro propósito es que casi todas ellas asumen con naturalidad la incorporación de resultados procedentes de otros campos de la investigación (Aróstegui 1995: pp. 129 y 133).

La postmodernidad, entendida como una actitud intelectual basada en la pérdida de confianza en el conocimiento científico de la historia, representa una visión cercana a la que propugna el llamado "giro lingüístico" en la filosofía de fin de siglo. El historiador debe abandonar la ilusión de contribuir a la comprensión objetiva de la historia puesto que la "evidencia" y el "dato" se difuminan y pierden su objetividad al ser interpretados. La buena o mala historia dependerá en última instancia de la forma en la que ésta es narrada más que en el grado de rigurosidad de las fuentes utilizadas. Este último

\footnotetext{
18 Sus postulados tal vez no puedan ser aprovechados desde una perspectiva tradicional de la historia de la arquitectura, pero parece que los análisis de variables mensiocronológicas efectuados sobre determinados elementos constructivos se aproximan a esta visión estadística (Quirós 1996).
}

aspecto explica la nula incidencia de la postmodernidad en el estudio de la arquitectura histórica.

Mucho más relevante resulta en nuestro ámbito de estudio la aplicación del concepto de microhistoria ${ }^{19}$. Se trata, a grandes rasgos, de una redefinición de los aspectos instrumentales de la observación histórica: reducción de la escala, análisis microscópico y una intensiva labor de estudio de los documentos. Esta nueva orientación permite revisitar aspectos ya estudiados que, al verse reducidos en su foco de observación y aumentar la intensidad, pueden mostrarse completamente nuevos (Levi 1993: p. 126, Pizza 2000: p. 59). Dicho modelo de análisis encierra gran potencial a la hora de estudiar ciertos fenómenos socio-antropológicos en su vertiente histórica a muy pequeña escala de observación (Aróstegui 1995: p. 143), como pudiera ser la construcción de un determinado edificio ${ }^{20}$.

Se podrá argüir que la HA asume algunos procedimientos amparados por esta renovación historiográfica. Es cierto que se ha experimentado una teórica superación de la dependencia respecto de las fuentes escritas o que en muchos trabajos se ha experimentado el paso del relato histórico a la "historia de las mentalidades". No estoy tan seguro, sin embargo, de que se pueda afirmar lo mismo con respecto a la crítica de autenticidad del documento construido, la visión desde la "larga duración" y la aplicación de la escala microhistórica, aspectos éstos que sí son consustanciales a la dinámica de trabajo de la AA.

Con todo, existe todavía un obstáculo aún mayor que condiciona a la HA a la hora de confeccionar un relato histórico plenamente actualizado. Me refiero a la noción de artisticidad, que ha sido definida como la cualidad que adquiere cualquier producción antrópica cuando se diseña para ser contemplada (Fernández Arenas 1982: p. 26). Este sistema selectivo margina intencionadamente a la mayoría de los objetos del pasado (edificios incluidos) que no disfrutan de cualidades artísticas ${ }^{21}$ (Furió 1990:

\footnotetext{
19 Aunque novedosa, esta perspectiva investigadora se sustenta gracias a ciertas aportaciones de la Escuela de los Annales, como la llamada "historia desde abajo" (Pizza 2000: pp. 45 y 47).

20 Demostrada tanto para modelos teóricos de épocas pre-industriales (Sánchez Zufiaurre 2007, Arce y Moreno 2012) como en los numerosos ejemplos publicados en esta misma revista. De hecho, aunque sin respaldo teórico, el término "microhistoria" es utilizado por Arce (2009: p. 24) para definir al relato constructivo generado tras cada lectura de paramentos.

21 Debray (1994: p. 108) denomina a las obras de arte "cuasiobjetos" puesto que son signo y a la vez cosa. Han sido seleccionados por un interés social tan huidizo como es el de "buen gusto" pero, al mismo tiempo, difícilmente pueden ser representativos de la sociedad de su tiempo precisamente por dicha excepcionalidad.
} 
p. 4). Corresponde a los historiadores del arte el establecimiento de los parámetros utilizados para medir tal condición. Innovación, creatividad, belleza o capacidad expresiva, entre otros, suelen ser algunas de las categorías elegidas al efecto. No podemos obviar que, en no pocas ocasiones, dichas variables responden a intereses ajenos a la obra, lo que merma objetividad al proceso de elección (Hauser 1975a: p. 270, Fernández Arenas 1982: p. 16, Furió 1990: p. 13, Hadjinicolaou 2005: p. 210).

Se ha dicho que lo "artístico" aparece cuando el placer (estético) ya no es tributario del encargo, esto es, cuando la labor del artista trasciende de lo comúnmente aceptado (Debray 1994: p. 192). Es precisamente esta consideración como algo excepcional lo que explica que el valor estético carezca de equivalente sociológico (Hauser 1975a: p. 81) y condicione el manejo de la obra de arte como fuente de información histórica plenaria. Esto no sucede con los documentos escritos, dado que "los malos testigos casi no existen y una narración, por muy imperfecta que sea, siempre puede contener noticias útiles" (Bloch 1999: p. $23)^{22}$. Solamente asumiendo los postulados de una historia del arte marxista es posible desembarazarse de esta pesada carga (Hadjinicolaou 2005: p. 209). Al verse libre del yugo de la estética, la producción artística se aproxima al concepto de "cultura material" propio de una Arqueología que, recordemos, en su evolución metodológica había ido reubicando dentro del análisis contextual a las categorizaciones de tipo morfológico (García Granados 1992: p. 61, Pierotti y Quirós 2000: p. 380).

\section{Acotación de los métodos en HA y su aplicación a la historia de la arquitectura}

Expuestas las inconveniencias que, a mi modo de ver, posee la HA a la hora de contribuir en la reconstrucción global del pasado, es justo evaluar la validez de sus métodos y enfoques dentro de un ámbito concreto de las sociedades históricas como es el de la arquitectura.

Partiré para ello de una afirmación incuestionable; "todo cuanto el hombre dice o escribe, todo cuanto fabrica, cuanto toca, puede y debe informarnos acerca de él" (Bloch 2006: p. 68). El edificio es testimonio de una voluntad colectiva que está presente en todas y cada una de las actividades

\footnotetext{
22 Más contundente aquí: “(...) la lección del desarrollo de la humanidad es muy clara: las ciencias se han mostrado tanto más fecundas y, por ende, tanto más serviciales según abandonaban más deliberadamente el viejo antropocentrismo del bien y del mal ¿Quién no se reiría hoy si un químico apartara a un lado un gas malo, como el cloro, y a otro, un gas bueno como el oxígeno? (Bloch 2006: p. 138).
}

que contribuyen a su levantamiento, su modificación y, en ocasiones, destrucción (Pizza 2000: p. 61). No cabe duda de que nos encontramos ante un "documento construido" (Caballero 1996: p. 56, Azkarate 2002: p. 58, Mandoul 2005: 139) que, con frecuencia, posee valores estéticos que obligan a enfocar su estudio desde una perspectiva histórico-artística. Las dudas planteadas obligan a interrogarnos en dos direcciones; ¿cuál es el bagaje epistemológico con el que HA cuenta para el análisis de un edificio?, ¿podemos aplicar al estudio de la arquitectura todos los métodos y enfoques que le son propios?

La plurivalencia del objeto artístico ha provocado una preocupante variedad de prácticas profesionales dentro de la misma disciplina ${ }^{23}$ (Fernández Arenas 1982: p. 18). El panorama es tan sumamente complejo que tal vez ayude a comprenderlo este símil. Hemos de pensar en un árbol de gruesas ramas que corresponden a la tradicional división de las llamadas "bellas artes". Desde ellas parten, a su vez, tantas ramificaciones como variables cronológicas, geográficas, técnicas o materiales encierra la producción artística ${ }^{24}$. La plurivalencia de lo que denominamos "obra de arte" ha contribuido a confundir enfoques, multiplicidad de puntos de vista y diversidad interpretativa con método de aproximación al objeto. Esta es la lectura que se desprende de un brevísimo repaso por la génesis y evolución de nuestra disciplina.

Aunque tal vez resulte sorprendente, la rama ocupada por la arquitectura no ha sido unánimemente considerada una categoría de estudio por parte de la HA. La explicación se encuentra en la propia naturaleza del edificio, definido ya por Vitruvio como una suma de valores

\footnotetext{
${ }_{23}$ Una división inicial se establece entre historiadores y críticos de arte. Como se ha explicado, esta diversificación profesional deriva directamente de la dualidad estética e histórica propia de la obra de arte.

${ }^{24}$ A través de un sencillo ejercicio es posible constatar la magnitud de aquello que etiquetamos como obra de arte. Si elegimos nuestra trayectoria investigadora siguiendo las ramas pintura, barroca, española, al óleo, podríamos situarnos frente al estudio de un Zurbarán. Si, por el contrario, tomamos la senda de artes decorativas, románicas, anglosajonas, orfebrería, penetraríamos en el terreno de piezas extraordinarias como el candelabro de Gloucester (siglo XII) del Victorian \& Albert Museum. Si tomamos la vía de la arquitectura, antigua, griega, en mármol, nos hallaríamos frente, por ejemplo, al Partenón de Atenas. Quienes se embarcan en el estudio de cada una de esas obras forma parte del colectivo genérico de "historiadores del arte", comparten un método de aproximación objetual basado en el estudio de las fuentes y en la observación directa. Sin embargo, sus enfoques interpretativos dependerán del objeto de estudio, la formación y a las circunstancias de cada uno de ellos. El nivel de especialización resulta fundamental si se quieren cosechar resultados positivos. Tratar de recorrer simultáneamente varias de las ramas de este árbol conduce a la debilitación de nuestra profesión. La pluralidad semántica de la obra de arte como objeto de estudio que, en opinión de ciertos teóricos, difumina el método histórico artístico y condena a su deslegitimación científica, debería ser mitigada a través de la especialización.
} 
constructivos, utilitarios o estéticos. Tanto los medios de análisis como los resultados variarán sustancialmente en función de la prevalencia de una u otra dimensión (Zevi 1951: pp. 17 y 150, Vilà 1990: p. 92, Pizza 2000: p. 80). Winckelmann y Lessing postulaban que lo importante en la actividad constructiva es la práctica, y por ello excluyen la arquitectura de sus trabajos dedicados al arte de la antigüedad (Kultermann 1996: p. 148), mientras que Wölfflin cuestiona la posibilidad de que el estilo de determinadas épocas pueda verse reflejado en su arquitectura (Gombrich 1997: p. 268). Croce excluía la arquitectura de la HA y, sin embargo, Longhi "che era più crociano di Croce" la considera una de las grandes artes (Carandini 1988: p. 32). Posturas como la de Zevi (1951: pp. 15 y 31), priorizan el elemento funcional por encima de los otros dos, anulando prácticamente la dimensión técnica.

Más allá de posicionamientos dogmáticos, a día de hoy resulta incuestionable que atender exclusivamente a la venustas vitruviana, obviando función y técnica, resulta un gravísimo error de planteamiento que conduce a la improductiva realización de análisis epidérmicos. Es preciso entender la arquitectura más como un "proceso" que como un "objeto" inerte (Pizza 2000: p. 123). Todo edificio es resultado de un procedimiento que se inicia con diseño ideal y concluye cuando ha podido ser materializado gracias a la disponibilidad de conocimientos técnicos y materiales. Su estructura, sea inicial o resultante de las lógicas modificaciones, puede - aunque no tiene porqué - contener en sí misma, o servir de soporte para, elementos artísticos con significados y funciones que varían al mismo ritmo que lo hace el propio edificio. La HA, durante sus más de dos siglos de vida, ha sabido dotarse de herramientas precisas para el estudio e interpretación de tales elementos.

Muy lejos queda la concepción elitista y precientífica motivadora de los primeros trabajos que, allá por el siglo XVIII, se interesaban en la reconstrucción de la biografía del artista como genio creador y que ponían el acento sobre la relación entre espíritu nacional y producción artística. La simplista concepción de una arquitectura que unía su suerte a la de un determinado pueblo para conformar un estilo constructivo resulta hoy día inadmisible (Kultermann 1996: p. 149).

Durante la segunda mitad del siglo XIX, la HA alcanzó una notable madurez científica que fue avalada tanto por su incorporación al mundo universitario (Borrás 2001: p. 17) como por el inicio de una fecunda relación con los cada vez más modernos museos (Kultermann 1996: p. 216). Tras la inicial reacción en contra del espiritualismo romántico, basada en la depuración del método filológico y del acercamiento a las fuentes, se viró hacia un positivismo que convertía al historiador del arte en experto catalogador de obras a partir de su análisis técnico y material (Fernández Arenas 1982: p. 48, Mandoul 2005: p. 140). Algunos protagonistas de este proceso procedían del ámbito de los estudios arquitectónicos, como Choisy o Semper. Este último llegó a jerarquizar los tres rasgos que determinan la creación de toda obra de arte: material, técnica y función. La evolución posterior de la disciplina hacia postulados más teóricos e ideales, explica la negativa opinión que buena parte de los investigadores continúa manteniendo hacia los trabajos de catalogación como fin en sí mismos (Pächt 1986: p. 51, Borrás 2001: p. 72). Una crítica ecuánime de este procedimiento, no obstante, no debería pasar por alto que las circunstancias culturales en las que surgió justifican plenamente su aplicación; incremento de la tutela del patrimonio cultural por parte de los estados, primeros pasos en las políticas de conservación y nacimiento de los museos. Coincido con Pizza (2000: p. 88) cuando señala que la posterior denuncia que el formalismo vierte sobre el determinismo semperiano coartó momentáneamente el desarrollo de investigaciones destinadas a calibrar la incidencia que sobre la arquitectura ejercen factores exógenos de tipo material y social.

Durante la segunda mitad del siglo XIX se produjo una reacción formalista contra el positivismo mayoritariamente protagonizada por historiadores del arte de la llamada Escuela de Viena y que resulta trascendental por muchos motivos. Fue a partir de entonces cuando el componente artístico comenzó a superar la subordinación respecto del contenido histórico presente en toda obra (Kultermann 1996: p. 213). Aun a riesgo de simplificar, el formalismo trataba de explicar el hecho artístico aislándolo del contexto en que surge y considerando sus variaciones a partir de un proceso exclusivamente estético. "El contenido artístico propio de la obra de arte consiste en la forma" (Fiedler 1990: p. 16), bajo esta premisa se condena la visión filosófica según la cual la belleza/forma depende de un elemento externo como es la idea y nace el concepto de "pura visualidad" que, trasladado a un colectivo, desemboca en lo que Riegl denominó "voluntad artística"25 (Pizza 2000: p. 90). Esta "voluntad", entendida como instinto/impulso formal o

\footnotetext{
25 “ (...) algo en el hombre, que nos permite encontrar placer en la belleza de las formas y que ha creado libre e independientemente las combinaciones geométricas de líneas, sin introducir primero un vinculo material" (Cfr. en Kultermann 1996: p. 220).
} 
energía abstracta, actúa como motor para la evolución de la HA (Pächt 1986: p. 91, Kultermann 1996: p. 221). Una de las claves que explica su éxito es que esta concepción "endogenética" del fenómeno artístico hizo saltar por los aires la teoría evolutiva de los estilos impuesta por Winckelmann (Fernández Arenas 1982: p. 93), relativizando así el maniqueísmo cualitativo de los estilos.

La concepción de la belleza como reflejo de valores culturales pasó a un segundo plano y se reivindicaron periodos artísticos que habían sido tachados tradicionalmente como decadentes. Al mismo tiempo se abandonó el interés por los datos documentales, muy especialmente por los de naturaleza biográfica y los que informaban de las condiciones sociales en las que la obra había sido gestada. La exaltación de una belleza residente en la forma condujo a la sobrevaloración del camino filosófico (Debray 1994: p. 104) en detrimento de la perspectiva materialista y de la curiosidad por los procedimientos técnicos. La Escuela de Viena, en definitiva, auspició el que una parte de la historiografía de la HA se introdujera en el siglo XX liberada de la supuesta tiranía del documento priorizando, en cambio, el estudio directo de la obra como fórmula para la obtención de conclusiones de naturaleza estética. Hay quien establece en este punto el origen de un "método" puramente histórico-artístico (Kultermann 1996: p. 227), pero, en mi opinión, se trata estrictamente de un enfoque ${ }^{26}$ que cortocircuita la relación arte/sociedad y sustrae a la obra de arte una gran parte de su capacidad para construir relatos históricos. En el caso particular de la arquitectura, supuso la adopción de una perspectiva de investigación parcial, puesto que parte de la consideración del edificio como estructura para ser vista y no para ser utilizada (Pizza 2000: p. 87).

A comienzos de siglo pasado, la posesión de un método propio que independiza el "hecho estético" a la vez que relativiza la importancia de las fuentes documentales y obliga al conocimiento exhaustivo de la obra, abonó el terreno para el florecimiento de nuevos o renovados enfoques, muchos de los cuales no son aplicables al estudio del edificio ${ }^{27}$.

\footnotetext{
${ }^{26}$ Remito al lector a la importante diferencia que, bajo mi punto de vista, se debe establecer entre "métodos" y "técnicas" o "enfoques". Vid. Supra.

27 Por este motivo no me detendré en el enfoque biográfico. Aunque la trayectoria personal y formativa de un arquitecto puede llegar a explicar determinados rasgos del edificio, esta perspectiva es inaplicable en estructuras de menor entidad o en las que resulta imposible conocer el nombre de su autor. Por esto mismo la psicología del artista (Furió 1990: p. 28) me parece que carece igualmente de repercusión. Tampoco prestaré atención a la perspectiva lingüística de la imagen artística (Fernández Arenas 1982: p. 128, Borrás 2001: p. 89), si bien abre un interesante campo de trabajo que, honestamente, desconozco si ha sido explorado en el caso de la arquitectura.
}

Entre todas ellas destaca por su importancia la redefinición del concepto de estilo, elemento clave como parámetro de comparación y análisis de nuestro método. Fueron desechadas las explicaciones simplificadoras que concebían sus formas como el reflejo romántico del espíritu de una nación o como predeterminación de las posibilidades técnicas o materiales. En su lugar se optó por denominaciones complejas que, partiendo de las anteriores, fueron completadas con ideas procedentes de nuevos enfoques sociales y simbólicos.

Para Riegl y Wölfflin, el estilo se debe buscar en ciertas formas a las que el ser humano responde instintiva y colectivamente (Gombrich 1997: p. 266). Esta definición le despoja de cualquier significación histórica y, en consecuencia, también lo empobrece (Hadjinicolaou 2005: p. 89). Coincide parcialmente con ellos Schapiro (1953: p. 278), quien considera que el origen del estilo en el seno de un grupo se debe, no a una reacción abstracta, sino que actúa como reflejo de una "personalidad colectiva" forjada en un determinado contexto social. Esta visión, y la de otros como Hauser (1975a: p. 97), ayudó a restituir al estilo su perdida capacidad para trasladar informaciones de tipo contextual. Antal añade que el contenido se combina con la forma para la configuración del estilo, abriendo así la puerta a su interpretación en clave marxista, o lo que es lo mismo, un aspecto simbólico más de la ideología dominante, en la línea de otros como el gusto o la moda (Hadjinicolaou 2005: p. 12). Finalizado este proceso de decantación, el estilo ya no será jamás el rasgo definidor de un determinado periodo histórico ni tampoco reflejo de identidades culturales, pero sí podrá ser depositario de valores que nos informan acerca de condiciones sociales o ideológicas.

Pese a lo que pudiera pensarse, la actitud de los propios historiadores del arte no ha sido, ni mucho menos, complaciente con el uso del estilo (Schapiro 1953: p. 279, Fernández Arenas 1982: p. 147). Al contrario, se ha cuestionado su encorsetada tendencia a la jerarquización que desemboca en la compartimentación artificial y la simplificación del fenómeno artístico. En línea con el pensamiento postmoderno, es frecuente la crítica hacia la adjetivación como método para la definición de un estilo, lo que acaba por categorizar a cuantas obras engloba. Tan profunda ha sido esta autocrítica que sorprende el grado de coincidencia con las vertidas desde

La historiografía española permaneció ajena a este proceso de renovación hasta bien entrado el siglo XX, provocando un evidente déficit metodológico (Borrás 2001: p. 70). 
la Arqueología. Desde esta disciplina se le acusa - con razón - de falta de precisión a la hora de servir como herramienta de datación (Parenti 1988: p. 282, Mannoni 1988: p. 405, Arce 2009: pp. 24 y 25, Tabales 2011: p. 68). Sin embargo, otras denuncias han de matizarse a la luz de lo ya expuesto, como la de que el estilo responde únicamente a la forma sin tener en cuenta otros elementos generadores como la materia (García Granados 1992: p. 61).

Creo que el concepto de estilo así decantado y asumiéndolo como algo hipertrofiado, utópico y abstracto de una realidad naturalmente más compleja (Hauser 1975a: p. 95), debe seguir siendo considerado la principal variable de análisis en la aplicación del método comparativo (Miranda 2000: p. 515). Despliega todo su potencial como herramienta de aproximación a horizontes sociales de los que emanan formas, materiales y contenidos particulares. Renunciar a ello debilita nuestra práctica profesional.

Algunos historiadores del arte lo consideran erróneamente como la equivalencia al tipo arqueológico ${ }^{28}$ (Vilá 1990: p. 109, Carrero 2008: p. 16). Recordemos que la Arqueología redimensionó desde temprano su interés por los objetos considerándolos productos antrópicos clasificables técnica y materialmente cuyo valor aumenta al hallarse dentro de un determinado contexto (Mannoni 1988: p. 403). La tipología, así concebida, se construye uniendo la forma a la posición que la pieza ocupa dentro de la secuencia estratigráfica, igual que sucede con los fósiles geológicos (Caballero 1995: p. 38, Caballero y Utrero 2013: p. 428). Al desprenderse del lastre que suponía la noción de "artisticidad", el tipo arqueológico aplicado al estudio del edificio permite la ordenación de elementos, sea cual sea su aspecto, que, contextualizados estratigráficamente y relacionados con ambientes productivos prudentemente acotados desarrolla una enorme capacidad para ofrecer cronologías (Sánchez Zufiaurre 2007). Es más, nada impide proceder a la "tipologización" de objetos con valor artístico incluidos en las fábricas históricas, pues basta con tener en cuenta los rasgos frecuentes de la catalogación estilística entre las variables que definen el tipo.

Otro de los enfoques más comunes en la historiografía del siglo XX es el iconográfico/iconológico, sistematizado por Panofsky (1972) a partir de los estudios

\footnotetext{
28 Aclaro que el tipo arquitectónico definido en la obra clásica de Pevsner (1979) es, en realidad, una particular, jerarquizada y, hasta cierto punto, simplificada trasposición del estilo en términos taxonómicos desde las otras artes a la historia de la arquitectura. De acuerdo con su planteamiento, el tipo/estilo, se crea en los edificios monumentales y, desde ahí, emana hacia la arquitectura puramente funcional.
}

culturales e icónicos de Burckhardt y Warburg. Su punto de partida es el siguiente: una forma desconectada de toda idea previa pero surgida a partir de la voluntad artística colectiva puede ser contenedora de símbolos y significados profundos. Mediante la observación iconográfica se accede al contenido convencional residente en la forma que, sometida posteriormente a un análisis iconológico profundo, puede llegar a revelar significados atribuibles exclusivamente al comportamiento social de un determinado grupo o persona ${ }^{29}$.

Pese a lo que pudiera pensarse, su ámbito de aplicación rebasa ampliamente la frontera de las artes figurativas. Así lo demuestran trabajos como los de Krautheimer (Kultermann 1996: p. 297) o Wittkower (Pizza 2000: p. 99), en los que parte del análisis arquitectónico consiste en la interpretación iconográfica e iconológica de determinadas planimetrías. El símbolo utiliza la imagen como vehículo de traslación, de lo que se deduce que pueda materializarse tanto a través de la forma como del contenido, pero también mediante la técnica o el material $^{30}$. Conviene recordar que estos componentes no son exclusivos de la creación escultórica y pictórica, sino que también se dan cita en procesos constructivos.

Si la iconografía recupera la conexión entre obra de arte y comportamiento colectivo a nivel simbólico, este mismo recorrido, en términos intelectuales y técnicos, será restaurado a través del enfoque sociológico (Francastel 1972). Su planteamiento básico es el siguiente. El artista, al elegir una técnica a través de la cual materializar una idea, se convierte en portavoz del entorno que le rodea. La obra finalizada es portadora de una jugosa información de carácter social que atañe, no sólo a los agentes que participan directamente en su realización, sino que va mucho más allá. Incluso los individuos que no participan de la creación son sensibles a los valores que permiten su existencia y contemplación. Esta variante interpretativa de la producción artística recupera, aunque matizada, uno de los elementos que había sido marginado por la Escuela de Viena. La forma no sólo traslada valores eternos indescifrables por ser fruto de una abstracta voluntad artística, sino que éstos pueden ser descodificados en términos sociológicos $\mathrm{y}$, añadiría, también históricos.

\footnotetext{
${ }^{29}$ Aunque pueda resultar llamativo, Carandini (1988: p. 32) considera la iconografía, junto con la estratigrafía y la tipología, parte fundamental de la Arqueología.

${ }^{30}$ Para Debray (1994: p. 54), no conviene perder de vista el componente técnico en el conjunto de la interpretación simbólica puesto que "un símbolo sólo puede actuar si es trasmitido...”. Pächt (1986: p. 85) advierte del riesgo que supone desviar la atención sobre el contenido dejando en penumbra el modo de representación en aras del cientifismo que aparentemente reviste los estudios iconográficos.
} 
Como parte del comportamiento social normativizado, la producción artística (y la arquitectónica especialmente) puede ser analizada atendiendo a los parámetros básicos de toda creación humana; producción, distribución y recepción (Furió 1990: p. 29).

El arte, así entendido, se convierte en valioso instrumento para la aproximación a sociedades del pasado (Hauser 1975a: p. 243). Adecuadamente interrogado nos transmite datos de naturaleza económica y política relativos a la sociedad que lo crea. Dichas informaciones complementan aquéllas de carácter religioso, moral o filosófico que pudieran extraerse a partir del análisis simbólico (Schapiro 1999: p. 115). Pero ¿cuál es la fórmula que, partiendo de los elementos de producción, nos permite extraer noticias de este tipo?

Desde comienzos del siglo XX, teóricos como Focillon volvieron a reivindicar el papel desempeñado por la técnica en la construcción de la forma artística (Gombrich 1997: p. 272). La sociología del arte situó el componente tecnológico al mismo nivel del intelectual y se recuperó el perdido interés hacia los procedimientos manuales ${ }^{31}$ (Francastel 1972: p. 92, Hauser 1975b: p. 19). Para el caso concreto de la arquitectura, la equiparación de las capacidades técnicas a las intelectuales resulta crucial. Si la producción de un edificio se divide en proyección y construcción, resulta fácil comprender que tan importante es la posibilidad técnica para proceder a su levantamiento como el diseño ideal sobre el plano (García Granados 1992: p. 62).

La técnica, en sentido amplio, evoluciona en consonancia con las circunstancias económicas y, por ello mismo, es natural que se ponga al servicio de la clase social dominante. Quienes conforman la élite tienden a establecer el monopolio de los medios de producción (también los destinados a la elaboración artística) utilizándolos como eficiente vehículo para la traslación de su ideología (Francastel 1972: p. 12). Vemos, por lo tanto, que una de las bases teóricas de la sociología del arte coincide con los planteamientos del materialismo histórico definido por Marx y Engels cuyo valor científico acapara numerosos elogios por su empirismo de probada aplicación práctica ${ }^{32}$.

\footnotetext{
31 Lo que no impide que se mantenga todavía viva la discusión que, en términos historiográficos, enfrentó a Semper (técnica) vs Riegl (forma-estética). Zevi (1951: p. 124), en lo referido a la arquitectura, considera que la forma va por delante de la técnica. En la misma línea se expresa Schapiro, para quien "un método de cortar piedra cambiará menos rápidamente que las formas del escultor o arquitecto" (Schapiro 1953: p. 280 y 1999: p. 74).

${ }^{32}$ Tal es su relevancia científica que autores como Hauser (1975a: p. 263) llegan a escribir que "más tarde o más temprano, de buen o mal grado, explícita o implícitamente, uno tendrá que darse a conocer como realista o idealista,
}

El marxismo se basa en la idea de que es el poder económico el que determina tanto el político como el ideológico, lo que conduce inevitablemente a la lucha de clases. Un enfoque marxista de la historia del arte tratará de indagar en el papel desempeñado por la producción de las obras dentro de estas relaciones de dependencia (Hadjinicolaou 2005). El "estilo" se interpreta como producto simbólico de la clase dominante, y su presentación (suma de forma y contenido) en la obra (o del edificio) es depositaria de la ideología de dicho grupo. Lo que la historiografía tradicional ha llamado "belleza" no es más que el placer que experimenta el individuo al reconocer dicha ideología, por ello independiente del efecto estético ${ }^{33}$. Investigar sobre la producción y recepción de la obra obliga a intentar reconstruir las condiciones que auspiciaron su producción, así como a aproximarse a las ideologías de las diferentes clases que han participado de su creación, modificación y recepción hasta nuestros días.

El recorrido por las variantes interpretativas surgidas a lo largo del siglo pasado concluye en el enfoque espacial, perspectiva que reivindica la tridimensionalidad de la arquitectura como pauta fundamental a la hora de construir su concepción histórico-artística (Zevi 1951). Tridimensionalidad real — al contrario de lo que sucede en la pintura - que envuelve a la figura humana - por ello distinta a la de la escultura - y que requiere del diseño de estrategias adecuadas que permitan recomponer el espacio generado por las estructuras construidas. A partir de la definición de sus características y dimensiones podrán atisbarse funciones y emitir interpretaciones de tipo político, social, religioso, etc. Se entiende así que las contribuciones filológicas, formales y técnicas resultan "epidérmicas" $y$, por lo tanto, insuficientes para comprender el edificio histórico en toda su magnitud.

El interés, la viabilidad y la actualidad de todos estos enfoques resulta incuestionable. Comprobarlo resulta sencillo. Basta con realizar una mínima cata entre la extensísima bibliografía dedicada al estudio artístico de la arquitectura. No me cabe ninguna duda de que su

como partidario o adversario de la concepción materialista de la historia". Debray (1994: pp. 102 y 105) concluye diciendo que "se habla mucho de arte y poco de máquinas: tradicional defecto de los hombres de ideas y sobre todo de los estetas", reflexión que fundamenta en el testimonio de algunos artistas como Renoir, quien decía que "la pintura no es una ensoñación. Es ante todo un oficio manual y hay que practicarlo como un buen obrero".

33 Desde la óptica marxista, la ideología burguesa considera "arte" únicamente las obras "mayores", simplificación interesada que está obligada a superar una nueva HA repensada desde esta perspectiva (Hadjinicolaou 2005: p. 21). 
adecuada combinación permite afrontar con garantías la extrema complejidad de la actividad constructiva en la que, como se ha expuesto, confluyen múltiples factores ideológicos, materiales y técnicos (Pizza 2000: p. 118). Esto, sin embargo, no impide llamar la atención sobre una objeción crucial para dimensionar la discusión que aquí se está planteando.

Retomemos por un instante el esquema teórico del trabajo del historiador del arte utilizado en el tercer punto de este mismo artículo. Basándonos en él, se justifica que estos enfoques tengan cabida dentro del nivel interpretativo de la investigación histórico-artística. Utilizando un léxico científico han de ser considerados como técnicas propias de nuestra disciplina. Es un error pensar en ellos como opciones válidas frente a los utilizados tradicionalmente pues no ofrecen alternativa alguna de aproximación objetual. No se cuestiona su utilización como medio para encontrar respuestas al sentido o al propósito cultural con el que fue levantado el edificio (Boto y Martínez 2010: p. 73). Pero, ¿de qué edificio?, ¿el originario?, ¿el modificado una y otra vez para satisfacer nuevos usos o funciones?, ¿el restaurado (en no pocas ocasiones) con fines historicistas?

Todos estos interrogantes apuntan hacia una idea que resulta fundamental en toda actividad científica. Para que las interpretaciones sean correctas, es necesario que la aproximación objetual y contextual haya sido lo más rigurosa posible. Los datos así recogidos proporcionan confianza en las explicaciones que emanan de ellos. El historiador del arte cuenta para ello con herramientas básicas en su formación; lectura crítica de las fuentes y capacidad visual, descriptiva y comparativa. Éstas han permanecido ahí desde los orígenes de nuestra disciplina, mejoradas a través de la experiencia de sucesivas generaciones de investigadores. No se ha producido ninguna "revolución" epistemológica sino que, caso de considerarla como tal, esta renovación se circunscribe al ámbito teórico y especulativo. En mi opinión es un error cerrar la puerta a otros instrumentos analíticos de validez comprobada como es la $\mathrm{AA}^{34}$. Hacerlo equivale a renunciar a las posibilidades que ofrece la estratigrafía, un "método itinerante" cuya aplicación requiere únicamente de preparación teórica y rigor práctico.

\footnotetext{
34 Hago mía las palabras de Pizza (2000: p. 80) para quien "cualquier identidad cognoscitiva debería primeramente superar falaces divergencias disciplinarias, retomando en sentido operativo la concepción de un productivo espacio histórico, donde aparece como aspecto fundacional el reconocimiento de los mecanismos activos de intersección, intercambio y conmixitión más que la defensa de inexistentes —o en todo caso nocivos - ámbitos corporativos".
}

Los edificios - como ocurre con los textos, los materiales arqueológicos o las piezas artísticas - no hablan sino cuando se sabe interrogarlos (Bloch 2006: p. 67). Se muestran más parlanchines a medida que vertemos sobre ellos preguntas que trascienden de lo epidérmico. Si contamos con dos textos anónimos que relatan de forma muy similar el mismo acontecimiento histórico, su estilo servirá para descubrir original y copia (Bloch 1999: p. 22). Ahora bien, es habitual toparse con una artimaña todavía más insidiosa que consiste en utilizar el mismo estilo para modificar el texto original. Cuando eso sucede, es preciso acudir a otras herramientas para detectar este engaño ${ }^{35}$. Las interpolaciones también son muy frecuentes en el edificio y el estilo puede ser el vehículo utilizado para no levantar sospechas. Por fortuna, la "reintroducción" del elemento copiado deja suturas que son detectables con los instrumentos adecuados. Mientras en la diplomática la alteración del documento originario suele tener intereses espurios, lo habitual en arquitectura es que ésta venga motivada por el propio uso del edificio, lo que la convierte en una acción ciertamente habitual.

Si no se es capaz de detectar las interpolaciones en el documento/monumento, nuestra interpretación del mismo será con seguridad errónea. Allí donde no alcanza el estilo será aconsejable recurrir a otros métodos que, como la estratigrafía, facilitan esta tarea. Por supuesto, no bastará simplemente con identificar "el engaño" y será obligación descubrir los motivos que lo originaron. En última instancia, corresponderá al historiador del arte o al arqueólogo interpretar el valioso testimonio que encierra toda falsificación o imitación del original, sea sobre pergamino, sea sobre el muro.

\section{Una cooperación real y efectiva}

Desde mi experiencia personal considero que la visión estratigráfica del edificio, como estrategia para la realización del trabajo de campo, contribuye a aumentar la rigurosidad del análisis objetual y mejora la sistematización en la toma de datos. Al mismo tiempo no creo que la adopción de este método obstaculice la interpretación en clave histórico-artística de la información obtenida. El lector familiarizado con sus procedimientos habrá percibido que este modo de operar responde a buena parte de

\footnotetext{
35 "Ningún documento es inocente. Debe ser juzgado. Todo documento es un monumento que hay que saber desestructurar, desmontar. El historiador no sólo tiene que saber discernir la falsedad, evaluar la credibilidad de un documento, sino que tiene que desmitificarlo" (Le Goff 1981, Cfr. en Pizza 2000: p. 62).
} 
las exigencias de la "nueva historia". Bajo la perspectiva de un tiempo histórico continuo, cualquier fenómeno humano $-\mathrm{y}$ la construcción sin duda lo es ${ }^{36}$ - debe ser valorado en razón a sus mutaciones (Bloch 2006: p. 31 y Pizza 2000: p. 42). La estratigrafía nos proporciona las herramientas adecuadas con las que establecer una biografía completa utilizando las huellas que los cambios han legado en los alzados de un edificio.

Según Bloch, la "tribu" de los historiadores permanece obsesionada por el ídolo de "los orígenes" que explica el comienzo de un fenómeno. Por eso lo perseguimos sin descanso y, en ocasiones erróneamente, lo convertimos en la razón final del estudio. Así actuaban los arquitectos/ historiadores del XIX, puesto que decretaban el estilo originario y se procedía a la restauración depurando sus trazas originales. Pero, de forma menos excepcional de lo que se piensa, ocurre que para encontrar la luz es necesario llegar hasta el presente (Bloch 2006: pp. 33 y 50). Siguiendo estos postulados, la AA se aplica con la misma intensidad de análisis sobre todos y cada uno de los componentes del edificio, con independencia de sus cualidades formales o de su identidad estilística.

$\mathrm{Si}$ "la verificación necesita un esfuerzo, mientras que el simple hecho de creer no" (Bloch 1999: p. 21), efectuar un estudio de larga duración basado en la lectura de paramentos sobre un muro exige paciencia. Como contrapartida, posibilita la revisión crítica tanto del monumento como de las conclusiones alcanzadas por anteriores estudios pre-estratigráficos. Por la escala en la que se desenvuelve, todo análisis estratigráfico cumple los requisitos para ser considerado microhistórico. Se aparca el idealismo de las formas grandilocuentes en favor de la recogida minuciosa de datos, algunos de los cuales pueden resultar aparentemente insignificantes. Al mismo tiempo que se recompone completamente la secuencia constructiva del edificio se reescribe una historia que le es propia e irrepetible y se le restituyen las particularidades que el estilo atenúa. Aunque el protagonista del relato es indiscutiblemente el monumento, por sus páginas van desfilando personajes que participan, con distinta intensidad, en las acciones constructivas y destructivas que van configurando su aspecto. Entre estas personas se encuentran comitentes, arquitectos o restauradores, pero también canteros, albañiles, carpinteros o herreros cuyas dinámicas de trabajo no suelen quedar reflejadas en la documentación escrita.

\footnotetext{
36 "Los hombres y la naturaleza no dejan jamás de actuar sobre ella, evidenciando así su inherente realidad como proceso más que como objeto..." (Pizza 2000: p. 123).
}

Tampoco la Arqueología aplicada al estudio del monumento está en disposición de dar la espalda a las implicaciones estilísticas depositadas en una parte de los datos obtenidos. Atendiendo a los esquemas prefijados desde la HA es posible ordenar en horizontes artísticos (y por ello también culturales) los resultados procedentes del análisis estratigráfico (Brogiolo 1995: p. 32). La cooperación, además de beneficiosa, resulta ineludible ${ }^{37}$. Pero, dadas las tensas relaciones, ¿existe alguna fórmula que facilite tal colaboración? Bajo mi punto de vista, y pese a las opiniones contrarias, el camino hacia el entendimiento debería pasar por plantear una formación dúplice, preferentemente dentro de la educación reglada ${ }^{38}$. Historiadores del arte que asimilen y apliquen los instrumentos de la Arqueología estratigráfica (Brogiolo 1995: p. 32) y viceversa, que desde la AA se atienda a los resultados y se practiquen los métodos y técnicas propias de la $\mathrm{HA}^{39}$. Llego a esta conclusión a partir de mi propia experiencia en la que, como historiador del arte, he tenido la oportunidad de integrarme en un equipo de arqueólogos sin tener la sensación de estar facilitando la subordinación de mi disciplina (Boto y Martínez 2010: p. 273).

No tengo duda alguna de que un historiador del arte, con la adecuada formación teórica y el necesario rodaje práctico, está capacitado para trabajar como estratígrafo frente al edificio ${ }^{40}$. Ni la identificación de los estratos y de sus relaciones, ni la discusión a pie de obra constituyen un obstáculo insalvable. Al contrario que la Arqueología de subsuelo, destructiva por definición, la observación del alzado no suele alterar ${ }^{41}$ su secuencia estratigráfica ni lleva asociada la puesta en marcha de técnicas de excavación que nos son completamente ajenas ${ }^{42}$. Ni picos, ni paletas, ni cepillos, ni la estación total son aquí necesarios. La comprensión de los principios básicos de la estratigrafía (con las lógicas adaptaciones cuando se aplica sobre contextos construidos), la paciente observación microscópica, la discusión con los

\footnotetext{
37 "Se le due discipline si occupano di cose differenti, si vivrà in pace ma, secondo me, non ci saranno corti circuiti culturali di grande interesse" (Carandini 1988: p. 36).

38 Lo deseable sería el intercambio de asignaturas con contenido metodológico en los programas de estudio de los grados/másteres de Historia del Arte y Arqueología.

${ }^{39}$ Comparto completamente la opinión de Azkarate (2002: p. 60), para quien, con independencia de la labor desempeñada, sería necesario que los protocolos de la AA, y añadiría también de la HA, sean interiorizados por cuantos tenemos responsabilidad patrimonial, ya sea académica o administrativa.

40 Las obras de Boato y Torsello (2008) y Brogiolo y Cagnana (2012) son útiles para una primera toma de contacto teórica

${ }^{41}$ Aunque en ocasiones la lectura exige la eliminación de revestimientos.

42 Si bien lo recomendable es completar la secuencia del alzado mediante la excavación del subsuelo.
} 
compañeros, un lapicero y planimetrías adecuadas son los instrumentos necesarios para "excavar" el edificio.

Más allá de integrarse como uno más en el equipo, la presencia de un historiador del arte ejerciendo su oficio está suficientemente justificada ${ }^{43}$. Conviene no olvidar que la mayoría de los ejemplos estudiados han sido inventariados y protegidos merced a sus valores históricos y artísticos. Además, la fábrica suele actuar como soporte para obras de escultura y de pintura que deben ser estudiadas en combinación con métodos y enfoques propios de la HA.

El estilo, redefinido a partir de la reflexión teórica que ha sido expuesta líneas atrás, se convierte durante el trabajo de campo en instrumento eficaz (con la adecuada verificación estratigráfica) para señalar interfaces (Sánchez Zufiaurre 2007). Documentado en contextos estratigráficos, el estilo de ciertos elementos constructivos y ornamentales también constituye una variable tipológica capaz de ofrecer cronologías de notable precisión para espacios culturalmente acotados.

Como historiadores del arte, nuestra formación nos permite trascender la percepción y comprensión general de una imagen artística. Somos buenos conocedores de los convencionalismos culturales vigentes en una determinada época y, partiendo de ellos, efectuar una lectura simbólica del objeto (Fernández Arenas 1982: p. 165). Por eso mismo, la identificación de programas iconográficos completos o, al contrario, la detección de alteraciones del mismo, se convierte en herramienta para señalar soluciones de continuidad entre UEs durante la lectura estratigráfica. Desde luego, la interpretación iconológica de los datos recogidos es un material valiosísimo para lanzar hipótesis e interpretaciones en torno al medio social (especialmente religioso y político) en el que fue creado o modificado dicho programa y, en consecuencia, la fase constructiva en la que se inserta.

También en la fase interpretativa que sucede al análisis estratigráfico tienen cabida las lecturas sociológica $y$ materialista. La construcción es resultado de la interacción entre individuos de variada extracción que poseen distintas capacidades materiales y técnicas dentro de un marco socioeconómico e ideológico determinado. Bajo estas coordenadas descubrimos con sorpresa que la HA y AA confluyen en sus planteamientos respecto a los procesos de creación de la cultura material, si bien desde

\footnotetext{
43 Contar con nosotros no implica la degradación de nuestras capacidades. No piensa eso el arquitecto que realiza las planimetrías, ni el historiador que se sumerge en el archivo en busca de documentación o el técnico que desarrolla los análisis arqueométricos.
}

escalas distintas (García Granados 1992: p. 68). La HA actúa a escala supraestructural cuando inserta los datos de producción en la dinámica segregadora de los estilos. Por el contrario, la AA habla de "arqueología de la producción" cuando establece las características básicas de un taller que opera desde una escala infraestructural (Mannoni 1988: p. 417, Azkarate 2002: p. 57) o de la evolución de ambientes constructivos suprarregionales interconectados (Caballero y Utrero 2013). En consecuencia, tanto el alcance como el grado de fiabilidad de las conclusiones que, en el plano social, se desprenden de sendas maneras de trabajar serán sustancialmente diferentes.

El modelo teórico de aproximación a la arquitectura pre-industrial emitido desde la Arqueología, si bien no exento de crítica (Azkarate 2008: p. 12), considera como estructura básica de análisis los ciclos productivos (extracción, acarreo y manipulación) de todos y cada uno de los materiales utilizados en la construcción (madera, piedra, metal) con independencia de su calidad artística. Previo establecimiento de límites temporales y geográficos, es posible relacionar estos ciclos con las circunstancias sociales y las variaciones técnicas. Esta fórmula utiliza las capacidades tecnológicas y no las estilísticas como indicio mediante el cual calibrar la evolución de las prácticas constructivas. La base de este planteamiento resulta incuestionable cuando nos situamos en un horizonte antropológico. Las formas tal vez puedan ser reproducidas tras observarlas, capacidad inherente al género humano en cualquier tiempo y lugar, mientras que las técnicas necesitan ser transmitidas, aprendidas $\mathrm{y}$, sobre todo, aplicadas de manera ininterrumpida para evitar su olvido y consiguiente pérdida. Las huellas de todos estos procesos permanecen indelebles en los muros del edificio que, como si de un palimpsesto se tratara, aguarda impaciente su adecuada ordenación e interpretación.

En conclusión, la arquitectura es el punto donde convergen habilidades técnicas, posibilidades materiales e intereses ideológicos. El producto finalizado, sea considerado objeto artístico, sea tratado como mero producto material, requiere para su estudio de pluralidad metodológica y multiplicidad de enfoques. Pese a un origen común, la Historia del Arte y la Arqueología están hoy académicamente separadas por abstracción y delimitación de planos de realidad, desarticulación científicamente necesaria pero que tiene el inconveniente de ocultar los puntos que las unen (Debray 1994: p. 92). 


\section{Agradecimientos}

Este trabajo ha sido realizado en el marco del proyecto de investigación dirigido por Luis Caballero que lleva por título "Análisis arqueológico de la arquitectura Altomedieval en Asturias: II" (HAR2011-27579 Plan Nacional de $\mathrm{I}+\mathrm{D}+\mathrm{i})$. Agradezco profundamente la lectura del mismo y los comentarios a Luis Caballero y María de los Ángeles Utrero. También quiero dejar constancia de la ayuda prestada por los profesores Miquel Àngel Capellà, Daniel Ortiz, Laura Fernández y Tomás Spaccarelli.

\section{Bibliografía}

Arce, F. 2009: "Historia de Arte, Arqueología de la Arquitectura y el telescopio de Galileo", Arqueología de la Arquitectura, 6, pp. 21-29.

Arce, F. y Moreno, F. 2012: "La construcción de iglesias como herramienta para el conocimiento del territorio tardoantiguo y altomedieval en la meseta norte", en Caballero, L., Mateos, P. y Cordero, T. (eds.), El territorio. Visigodos y omeyas, pp. 97-122. CSIC, Mérida.

Aróstegui, J. 1995: Investigación histórica: teoría y método. Crítica, Barcelona.

Asti, A. 1973: Metodología de la investigación. Kapelusz, Buenos Aires.

Azkarate, A. 2002: "Intereses cognoscitivos y praxis social en Arqueología de la Arquitectura", Arqueología de la Arquitectura, 1, pp. 55-71.

Azkarate, A. 2008: "La Arqueología de la Arquitectura en el siglo XXI", Arqueología de la Arquitectura, 5, pp. 11-13.

Azkarate, A. 2010: “Archeologia dell'Architettura in Spagna”, Archeologia dell'Architettura, XV, pp. 17-28.

Barros, J. M. 2010: "La correlación de unidades estratigráficas en estructuras pictóricas", Arché, 4-5, pp. 31-36.

Bloch, M. 1999: Historia e Historiadores. Akal, Madrid [Ed. orig. en francés 1995: Histoire et historiens. A. Colin, París].

Bloch, M. 2006: Introducción a la historia. Fondo de Cultura Económica, México D.F [Ed. orig. en francés 1949: Apologie pour l'Histoire ou Métier d'historien. A. Colin, París].

Boato, A. y Torsello, B. P. 2008: L'archeologia in architettura: misurazioni, stratigrafie, datazioni, restauro. Marsilio, Venecia.

Borrás, G. 2001: Cómo y qué investigar en historia del arte. Una crítica parcial de la historiografia del arte español. Ediciones del Serbal, Barcelona.

Boto, G. y Martínez, A. M. 2010: "Historiar la Arquitectura medieval. Intersecciones epistemológicas de la Historia del Arte y la Arqueología de la Arquitectura", Arqueología de la Arquitectura, 7, pp. 263-275.

Brogiolo, G. P. 1995: “Arqueología estratigráfica y restauración”, Informes de la Construcción, 46, 435, pp. 31-36.

Brogiolo, G. P. 2002: “L'Archeologia dell'architettura in Italia nell'ultimo quinquenio (1997-2001)", Arqueología de la Arquitectura, 1, pp. 19-26.

Brogiolo, G. P. y Cagnana, A. 2012: Archeologia dell'architettura. Metodi e interpretazioni. All'Insegna del Giglio, Florencia.

Caballero, L. 1995: "Método para el análisis estratigráfico de construcciones históricas o "lectura de paramentos", Informes de la Construcción, 46, 435, pp. 37-46.

Caballero, L. 1996: "El análisis estratigráfico de construcciones históricas", en Caballero, L. y Escribano, C. (eds.), Arqueología de la Arquitectura, pp. 55-74. Junta de Castilla y León, Burgos.

Caballero, L. 2012: “A propósito del centenario del 711. Apuntes sobre método de la Arqueología de la Arquitectura", en Momplet, A. E., Moreno, F. J. y Silva, N. (eds.), 711: el arte entre la Hégira y el califato Omeya de al Andalus, Anales de Historia del Arte, 23, Vol. Ext. pp. 101-130.

Caballero, L. y Utrero, $\mathrm{M}^{\mathrm{a}}$ de los Á. 2013: “Cómo funcionaban los talleres constructivos en la alta Edad Media hispánica”, en Arízaga, B. et al. (eds.), Mundos medievales: espacios, sociedades y poder: homenaje al profesor José Ángel García de Cortázar y Ruiz de Aguirre, Tomo I, pp. 427-439. PUbliCan, Universidad de Cantabria, Santander.
Carandini, A. 1988: “Archeologia, architettura, storia dell'arte", en Francovich, R. y Parenti, R. (eds.), Archeologia e restauro dei monumenti, pp. 31-38. All'Insegna del Giglio, Siena.

Carrero, S. 2008: "Teoría y método en la Historia de la Arquitectura Medieval. Algunas reflexiones", en Seminari d'estudis històrics 2007: Arqueologia de l'arquitectura, pp. 5-27. Societat Arqueològica Lul-liana, Palma de Mallorca.

Debray, R. 1994: Vida y muerte de la imagen: historia de la mirada en Occidente. Ediciones Paidos, Barcelona [Ed. orig. en francés 1992: Vie et mort de l'image. Une histoire du regard en Occident. Gallimard, París].

Díaz-Andreu, M. 1995: "Arte y arqueología: la larga historia de una separación”, en Historiografia del arte español en los siglos XIX y XX, pp. 151-160. CSIC, Madrid.

Fernández Arenas, J. 1982: Teoría y metodología de la Historia del Arte. Anthropos, Barcelona.

Fiedler, K. 1990: Escritos sobre arte. Visor, Madrid. [Ed. orig. en alemán: 1896, Schriften über Kunst. Leipzig].

Francastel, P. 1972: Sociología en el arte. Alianza, Buenos Aires. [Ed. orig. en francés 1972: Etudes de sociologie de l'art, Denoël/Gonthier, París].

Freixa, M. 1990: "La historia del arte como historia. Las técnicas de investigación y el problema de las fuentes", en Introducción a la Historia del Arte, pp. 60-87. HUROPE, Barcelona.

Furió, V. 1990: "La historia del arte: aspectos teóricos y metodológicos", en Introducción a la Historia del Arte, pp. 3-59. HUROPE, Barcelona.

García Granados, J. A. 1992: "Historia del arte y arqueología. A propósito de arquitectura", en Coloquio hispano-italiano de arqueología medieval, pp. 61-72. Patronato de la Alhambra y Generalife, Granada.

Gombrich, E. H. 1997: "La psicología de los estilos", en Gombrich esencial. Textos escogidos sobre arte y cultura, pp. 257-293. Debate, Madrid [Ed. orig. en inglés 1996: The Essential Gombrich. Phaidon, Londres].

Hadjinicolaou, N. 2005: Historia del arte y lucha de clases. Siglo Veintiuno, México D. F. [Ed. orig. en francés 1973: Histoire de l'art et lutte des clases. F. Maspero, París,]

Hauser, A. 1975a: Sociología del arte, vol 1. Guadarrama, Madrid. [Ed. orig. en ingles 1951: The Social History of Art. Vintage Books, Nueva York].

Hauser, A. 1975b: Sociología del arte, vol. 2. Guadarrama, Madrid.

Kultermann, U. 1996: Historia de la historia del arte. El camino de una ciencia. Akal, Madrid. [Ed. orig.en ingles 1993: The history of Art History. Abaris Books, Nueva York].

Levi, G. 1993: "Sobre microhistoria", en P. Burke (ed.), Formas de hacer historia, pp. 119-143. Alianza, Madrid.

Mandoul, T. 2005: “Choisy et le positivisme historique. Questions de méthode", Livraisons d'histoire de l'architecture, 9, pp. 137-145.

Mannoni, T. 1988: “Archeologia della produzione”, en Francovich, R. y Parenti, R. (eds.), Archeologia e restauro dei monumenti, pp. 403-420. All'Insegna del Giglio, Siena.

Miranda, M. J. 2000: "Metodología aqueológica ao serviço da História de Arte", en $3^{\circ}$ Congresso de Arqueologia Peninsular, Actas, Vol. 1, Arqueologia peninsular. História, teoria e práctica, pp. 511-520. ADECAP, Oporto.

Pächt, O. 1986: Historia del arte y metodología. Alianza, Madrid. [Ed. orig. en alemán 1977: Methodisches zur kunsthistorischen Praxis. Prestel, Munich].

Panofsky, E. 1972: Estudios sobre iconología. Alianza, Madrid. [Ed. orig. en inglés 1939: Studies in iconology. Oxford University Press, Nueva York].

Parenti, R. 1988: "Sulle possibilità di datazione e di classificazione delle murature", en Francovich, R. y Parenti, R. (eds.), Archeologia e restauro dei monumenti, pp. 280-304, All'Insegna del Giglio, Siena.

Pevsner, N. 1979: Historia de las tipologías arquitectónicas. Gustavo Gili, Barcelona [Ed. orig. en inglés 1976: A History of Building Types. Princeton University Press, Princeton].

Pierotti, P. y Quirós, J. A. 2000: “Archeologia dell'architettura e storia dell'architettura: due discipline a confronto", en Brogiolo, G. P. (ed.), II Congresso Nazionale di Archeologia Medievale. Musei Civici, Chiesa di Santa Giulia. Brescia, 28 settembre-1 ottobre 2000, pp. 377-380. All'Insegna del giglio, Florencia. 
Pizza, A. 2000: La Construcción del Pasado. Reflexiones sobre Historia, Arte y Arquitectura. Celeste Ediciones, Madrid.

Quirós, J. A. 1996: “Indicadores cronológicos de ámbito local: cronotipología y mensiocronología”, en Caballero, L. y Escribano, C. (eds.), Arqueología de la Arquitectura, pp. 179-187. Junta de Castilla y León, Burgos.

Ripoll, O. y Ripoll, G. 1988: "Los conceptos de arqueología e historia del arte antiguo y medieval: apuntes historiográficos", Espacio, Tiempo y Forma, Serie II, Historia Antigua, t. I, pp. 411-426.

Ripoll, G. 1992: "Historia del Arte y Arqueología", en Arqueología, Hoy, pp. 89-94. UNED, Madrid.

Sánchez Zufiaurre, L. 2007: Erdi Aroko Erailuntza Teknikak. Arkeologia dokumentu berriak Arabako Goi Erdi Aroa aztertezeko. Técnicas constructivas medievales: nuevos documentos arqueológicos para el estudio de la Alta Edad Media en Álava. Universidad del País Vasco y Gobierno Vasco, Departamento de Cultura, Vitoria-Gasteiz.
Schapiro, M. 1953: "Style”, en Anthropology Today: Selections, pp. 278-303. University of Chicago Press, Chicago y Londres.

Schapiro, M. 1999: Estilo, artista y sociedad. Teoría y filosofía del arte. Tecnos, Madrid [Ed. orig. en ingles 1994: Theory and Philosophy of Art: Style, Artists and Society. G. Braziller, Nueva York].

Tabales, M. A. 2011: "Aportaciones de la arqueología medieval al conocimiento de las técnicas constructivas", en Graciani, A. (ed.), La técnica de la Arquitectura medieval, pp. 35-74. Universidad de Sevilla, Secretariado de Publicaciones, Sevilla.

Vilà, F. 1990: "La Arquitectura", en Introducción a la Historia del Arte, pp. 89-125. HUROPE, Barcelona.

Zevi, B. 1951: Saber ver la arquitectura. Ensayo sobre la interpretación espacial de la arquitectura. Poseidon, Buenos Aires [Ed. orig. en italiano 1948: Saper vedere l'architettura; saggio sull'interpretazione spaziale dell'architettura. G. Einaud, Turín]. 